\title{
Management of COVID-19
}

\author{
Mary John ${ }^{1}$ \\ 1Department of Medicine, Christian Medical College and Hospital,
Ludhiana, Punjab, India
}

Ind J Car Dis Wom:2020;5:227-229
Address for correspondence Mary John, MD, Department of Medicine, Christian Medical College and Hospital, Ludhiana, Punjab, 141008, India (e-mail: mjohncmc@gmail.com).

\section{Management of COVID-19}

The COVID-19 pandemic has been evolving since December 2019, and so has the understanding of the disease and its management. Siddiqi and Mehra in their paper on "COVID-19 illness in native and immunosuppressed states: A clinical-therapeutic staging proposal" have eloquently described the various stages of COVID-19 disease (-Fig. 1) along with some potential therapies. ${ }^{1}$ As the pandemic evolved, multiple observational studies were done without proper controls.

Since there are several ongoing studies/clinical trials, a simple treatment protocol could be adopted, based on the original staging of the disease along with the added throm-

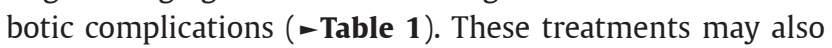
be subject to change as and when results of these studies are endorsed by various regulatory bodies (ICMR, IDSA FDA, etc.).

The management of COVID-19 is done in accordance with the Ministry of Health and Family Welfare, Govt. of India (updated on $3 / 7 / 2020)^{2}$

\section{Management of Mild COVID-19 Cases (Symptomatic influenza-like illness [ILI] without Pneumonia or Lung Signs)}

- May admit those with high risk in COVID care centers (CCC), community health center, district hospitals, or home isolation.

- Counsel the patients regarding worsening of symptoms and signs, specifically in those with comorbidities.

- Investigations at diagnosis: CBC,-NLR, X-ray chest, CRP, AST, ALT, D-dimer, LDH.
- Monitor pulse oximetry, temperature and respiratory rate every 2 to 4 hours or earlier if needed.

- Symptomatic treatment with paracetamol for fever and pain; antitussives for cough.

- Consider hydroxychloroquine (HCQ)-under strict supervision in those with comorbidities (MOHF-version 5; dated 3/7/2020).

- If there is worsening hypoxia (if drop in $\mathrm{SpO}_{2}$ ) or increase in respiratory rate $\geq 5 / \mathrm{min}$ from baseline, repeat $\mathrm{D}$-dimer, ABG, X-ray chest, consider giving prophylactic dose of anticoagulation, and refer to dedicated COVID health center (DCHC). ${ }^{3}$

- An initial dose of steroid may be administered only in the presence of hypoxia $(\mathrm{SpO} 2<94 \%)$.

\section{Management of Moderate COVID-19 Cases}

(Pneumonia-Clinical or Radiological, with or without Hypoxia; respiratory rate $[R R]>24 / \mathrm{min}$ )

- Admit in DCHC.

- Monitor $\mathrm{SpO}_{2}$, at least, every 2 hours along with RR.

- Investigations: CBC, X-ray chest, CRP, AST, ALT, D-dimer, LDH, ferritin, EKG, ABG.

- Oxygen to be administered (target SpO2: 92-96\%; 88-92\% in patients with chronic obstructive pulmonary disorder [COPD]); devices to deliver oxygen maybe via nasal prongs, mask, or masks with breathing/nonrebreathing mask (NRBM); if high-flow nasal cannula (HFNC) or simple nasal cannula is used, N95 mask should be applied.

- Promote "awake prone ventilation" (can be done in patients with oxygen requirement of $>4 \mathrm{~L}$, having a
License terms

DOI https://doi.org/
10.1055/s-0040-1718866. 
normal mental status and who are able to self-prone or change position with minimal assistance).

- Give prophylactic dose of anticoagulation if not contraindicated; if D-dimer levels are increasing, consider increasing to therapeutic doses of anticoagulation; consider imaging-computed tomography pulmonary angiography (CTPA), Doppler lower limbs and echocardiogram for thrombotic disease.

- Administer IV methylprednisolone or dexamethasone (if oxygen requirement is increasing or inflammatory markers are elevated). Do not start steroids if patient not on oxygen. Continue to review the duration of administration, according to the clinical response.

- Consider remdesivir (under emergency use authorization [EUA]) and convalescent plasma (off label use).

- Repeat CRP, D-dimer, and ferritin every 48 to 72 hours.

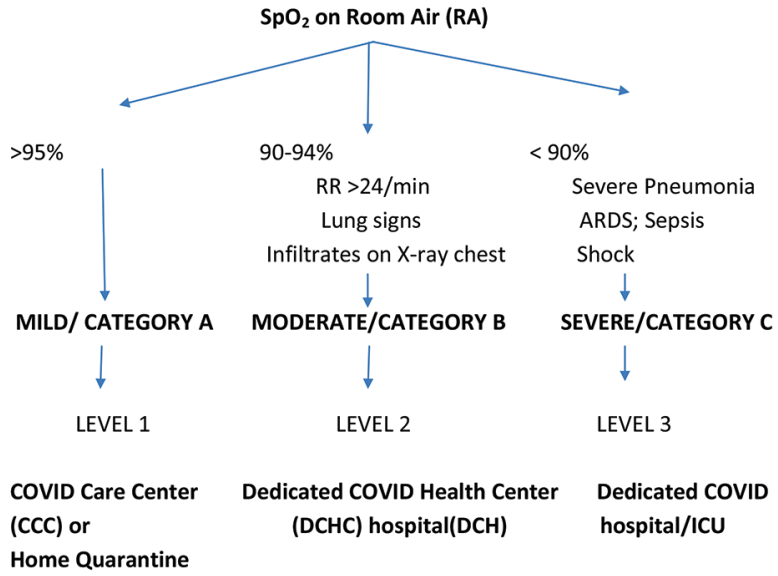

Fig. 1 Triaging of confirmed COVID-19 patients.
- Control comorbidities and consider empiric antibiotic therapy in elderly with comorbidities, immunocompromised individuals, and children $<5$ years of age.

- Close monitoring of patients with moderate COVID-19 is required for signs or symptoms like increasing oxygen requirement or hemodynamic instability; if present, shift to a DCHC.

\section{Management of Severe COVID-19 Cases (pneumonia with $\mathrm{RR}>30 / \mathrm{min} /$ acute respiratory distress syndrome [ARDS]/shock $/ \mathrm{SpO}_{2}<90 \%$ on right atrial [RA])}

- Admit to a DCHC.

- Investigations: CBC, X-ray chest, CRP, AST, ALT, D-dimer, LDH, ferritin, EKG, ABG.

- Continuous pulse oximetry and hemodynamic monitoring is mandatory.

- Oxygen support: target $\mathrm{SpO}_{2} 92$ to 96\% (88-92\% in COPD); escalate oxygen therapy as required; patients may be on noninvasive ventilation (NIV), NRBM, HFNC or need to be ventilated.

- Repeat D-dimer if escalating respiratory support needed.

- Continue anticoagulation with prophylactic dose and increase to therapeutic dose if D-dimer levels are increasing; consider imaging-CTPA, Doppler lower limbs, and echocardiogram for thrombotic disease.

- Give IV methylprednisolone/dexamethasone.

- Consider giving tocilizumab (Infectious Diseases Society of America [IDSA] guidelines $)^{4}$ in the context of clinical trial; rule out infection.

- Consider remdesivir (IDSA). ${ }^{4}$

- Prone ventilation if no contraindication (all intubated patients should also be proned).

- Management of ARDS/shock/sepsis (choose antibiotics to cover Pseudomonas and Staph).

Table 1 COVID-19: clinical and pathological staging

\begin{tabular}{|l|l|l|l|}
\hline & $\begin{array}{l}\text { Stage I } \\
\text { (early infection) }\end{array}$ & $\begin{array}{l}\text { Stage II } \\
\text { (pulmonary phase } \\
\text { IIA-no hypoxia } \\
\text { IIB-hypoxia) }\end{array}$ & $\begin{array}{l}\text { Stage III } \\
\text { (hyperinflammation phase) }\end{array}$ \\
\hline Severity of infection & $\begin{array}{l}\text { Mild (Cat A) } \\
\text { Viral response phase }\end{array}$ & $\begin{array}{l}\text { Moderate (Cat B) } \\
\text { Viral response phase + host inflam- } \\
\text { matory phase }\end{array}$ & $\begin{array}{l}\text { Severe (Cat C) } \\
\text { Host inflammatory response phase }\end{array}$ \\
\hline Clinical symptoms & $\begin{array}{l}\text { RR }<24 / m i n \\
\text { Mild constitutional symptoms- } \\
\text { fever }>\text { 99.6 }{ }^{\circ} \text {, dry cough }\end{array}$ & $\begin{array}{l}\text { RR } \geq \mathbf{2 4}<\mathbf{3 0 / m i n} \\
\text { Without (IIA) and with (IIB) } \\
\text { hypoxia, PaO2/FiO2 300 mm Hg }\end{array}$ & $\begin{array}{l}\text { RR } \geq \mathbf{3 0 / m i n} \\
\text { Severe pneumonia, RDS, SIRS, shock, } \\
\text { cardiac failure }\end{array}$ \\
\hline Investigations & $\begin{array}{l}\text { Lymphopenia; NLR }>3.13) \\
\text { Abnormal chest imaging; } \\
\text { transaminitis, low to normal } \\
\text { procalcitonin }\end{array}$ & $\begin{array}{l}\text { Elevated inflammatory markers } \\
\text { (CRP, LDH, IL-6, D-dimer, ferritin, } \\
\text { troponin, NT-pro-BNP elevation) }\end{array}$ \\
\hline Potential therapies & $\begin{array}{l}\text { Antivirals } \\
\pm \text { prophylactic dose of } \\
\text { anticoagulation }\end{array}$ & $\begin{array}{l}\text { Antivirals + anti-inflammatory } \\
\text { (steroids) } \pm \text { convalescent plasma + } \\
\text { prophylactic dose of } \\
\text { anticoagulation }\end{array}$ & $\begin{array}{l}\text { Anti-inflammatory } \pm \text { antivirals } \pm \\
\text { convalescent plasma }+ \text { prophylactic/ } \\
\text { therapeutic dose of anticoagulation }\end{array}$ \\
\hline
\end{tabular}

Abbreviations: ARDS, acute respiratory distress syndrome; NLR, neutrophil to lymphocyte ratio; RR, respiratory rate; SIRS, systemic inflammatory response syndrome. 


\section{Recommended Dosing Schedule}

HCQ: $400 \mathrm{mg}$ bd X 1 day followed by $200 \mathrm{mg}$ bd $\times$ 4days (avoid if QTc > $500 \mathrm{~ms}$ ).

Remdesivir: $200 \mathrm{mg}$ stat IV followed by $100 \mathrm{mg}$ OD IV for 4 days (interaction with HCQ); monitor liver function test.

IV Methylprednisolone: 0.5 to $1 \mathrm{mg} / \mathrm{kg}$ for 3 to 5 days.

IV Dexamethasone: 0.1 to $0.2 \mathrm{mg} / \mathrm{kg}(6 \mathrm{mg})$ OD for 10 days; use prednisolone or $40 \mathrm{mg} /$ day or hydrocortisone $80 \mathrm{mg}$ bd if pregnant or breast feeding.

Anticoagulation preferred with enoxaparin $40 \mathrm{mg}$ OD s/c or fondoparinux $2.5 \mathrm{mg}$ OD s/c or unfractionated heparin 5000 units BD s/c.

Therapeutic dose of enoxaparin: $1 \mathrm{mg} / \mathrm{kg}$ BD s/c.

Tocilizumab: $400 \mathrm{mg}$ stat ( $8 \mathrm{mg} / \mathrm{kg}$ ); maximum of 2 doses. Monitor IL-6, CRP, ferritin.

Contraindicated in people living with HIV (PLHIV), active infections, tuberculosis (TB), active hepatitis, absolute neutrophil count (ANC) $<2000 / \mathrm{mm}^{3}$ and platelet count $<1,00,000 / \mathrm{mm}^{3}$.

Convalescent plasma: 4 to $13 \mathrm{~mL} / \mathrm{kg}$ (200 mL) single dose over 2 hours.

Avoid in patients with IgA deficiency or immunoglobulin allergy.

\section{Conflicts of Interest}

None declared.

\section{References}

1 Siddiqui HK, Mehra M. COVID-19 illness in native and immunosupressed states: a clinical-therapeutic staging proposal. J Heart Lung Transplant 2020 (e-pub ahead of print). doi: https://dx.doi.org/10.1016\%2Fj.healun.2020.03.01

2 Government of India, Ministry of Health and Family Welfare, Directorate General of Health Services (EMR Division); Version 5; dated 03.07.20. Available at: https://www.mohfw. gov.in/. Accessed July 10, 2020

3 Gupta A, Madhavan MV, Sehgal K, et al. Extrapulmonary manifestations of COVID-19. Nat Med 2020;26(7):1017-1032

4 Infectious Disease Society of America Guidelines on the treatment and Management of Patients with COVID-19 (updated18/6/2020). Available at: https://www.idsociety. org/practice-guideline/covid-19-guideline-treatment-andmanagement/. Accessed July 10, 2020 